\title{
Infectious Complications in Patients with Primary Glomerulonephritis over 10 Years: A Single-Center Experience in Turkey
}

\author{
Rezzan Eren Sadioglu ${ }^{a}$ Sahin Eyupoglu ${ }^{a}$ Siyar Erdogmus ${ }^{a}$ \\ Gizem Kumru Sahin $^{a}$ Fugen Yoruk $^{b}$ Sim Kutlay ${ }^{a}$ Kenan Keven ${ }^{a}$ \\ Sehsuvar Erturk ${ }^{a}$ Sule Sengul ${ }^{\mathrm{a}}$ \\ aDepartment of Nephrology, Ankara University School of Medicine, Ankara, Turkey; ${ }^{b}$ Department of Infectious \\ Disease and Clinic Microbiology, Ankara University School of Medicine, Ankara, Turkey
}

\section{Keywords}

Glomerulonephritis · Infection · Immunosuppression ·

Mortality

\begin{abstract}
Introduction: Infections can play an important role in the mortality and morbidity of patients with glomerulonephritis. However, the frequency of infectious complications in primary glomerulonephritis and their burden to the healthcare managements are not clear. Methods: We evaluated the infectious complications in patients with biopsy-proven focal segmental glomerulosclerosis, membranous glomerulonephritis, IgA nephropathy, minimal change disease, membranoproliferative glomerulonephritis, and chronic glomerulonephritis during the last 10 years in a single center. We recorded the demographic, clinical, and laboratory characteristics; treatment modalities; infectious episodes; and infection-related mortality and morbidity of the patients. Results: Of the patients, $154(63.6 \%)$ received immunosuppressive treatment and $88(34.4 \%)$ were followed up under conservative treatment. Overall, 118 infectious epi-
\end{abstract}

sodes were noted in 64 patients, with an infection rate of 0.20 per patient-year. Total infectious complications were higher in the immunosuppressive group than in the conservative group ( 42.1 vs. $23.3 \%, p=0.005$ ). Infection-related hospitalizations were also higher in the immunosuppressive group $(p=0.01)$. The most frequently infected area was the lungs (15.7\%). Although bacterial infections were the most common in both groups, $14.9 \%$ of the immunosuppressive group had cytomegalovirus (CMV) replication. Age $>50$ years (OR 2.19, $p=0.03$ ), basal serum albumin $<2.5 \mathrm{~g} / \mathrm{dL}$ (OR 2.28, $p=0.02$ ), cyclophosphamide (OR $2.43, p=0.02$ ), and cyclosporine (OR 2.30, $p=0.03$ ) were independently associated with experiencing infectious episodes. Conclusions: Because of high seropositivity for CMV in Turkey, it might be a wise approach to use prophylactic antiviral drugs in patients treated with immunosuppressive treatments. Close monitoring of patients with primary glomerulonephritis, especially those treated with immunosuppressive therapy, is important for reducing infection-related morbidity and mortality.

(C) 2020 The Author(s)

Published by S. Karger AG, Basel karger@karger.com www.karger.com/kdd

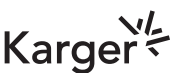

BOPEN ACCESS
(C) 2020 The Author(s)

Published by S. Karger AG, Basel

This article is licensed under the Creative Commons AttributionNonCommercial-NoDerivatives 4.0 International License (CC BYNC-ND) (http://www.karger.com/Services/OpenAccessLicense) Usage and distribution for commercial purposes as well as any distribution of modified material requires written permission.
Rezzan Eren Sadioglu

Department of Nephrology

Ankara University School of Medicine, Talatpasa Bulvari

No. 82, Altindag, Ankara 06230 (Turkey)

rezzanerensadioglu@gmail.com 


\section{Introduction}

Infection is a known complication of either glomerular diseases themselves or immunosuppressive treatments in patients with glomerular diseases. Possible explanations for the increased risk for infection in glomerular diseases consist of loss of IgG and complement factor B, zinc, and transferrin in the urine, which are all required for a normal immune function [1]. Years ago, infection was the major cause of death in patients with nephrotic syndrome [2]. Along with the increased remission of glomerulonephritis and wide usage of antibiotics, infection-related mortality has decreased; however, infections are still an important cause of mortality and morbidity [3].

Glomerulonephritis might be diagnosed as a primary disorder or as a part of a systemic disease, such as systemic lupus erythematosus (SLE), antineutrophil cytoplasmic antibodies-associated vasculitis (AAV), or thrombotic microangiopathy. Notwithstanding the fact that corticosteroids still have the most widespread use of all, immunosuppressive therapy usage has been developed, and there are different treatment choices for primary glomerulonephritis, such as cyclophosphamide, calcineurin inhibitors, mycophenolate mofetil (MMF), azathioprine, and rituximab. Although different agents may have their own side effects, infectious complications are common to all [4]. There are several previous studies dealing with the safety of several agents in selected populations [5-7]. However, very few studies have focused on the various infections and their effects on hospital outcomes in all primary glomerulonephritis in the developing part of the world. Turkey is a developing Eurasian country with a population of approximately 83 million people [8]. Despite cardiovascular diseases being the most prevalent causes of death in Turkey, communicable diseases are still a matter of concern. Almost ten thousand deaths occur every year in Turkey because of infectious diseases [9]. Additionally, higher cytomegalovirus (CMV) seropositivity rate has an important role in patients planned to receive immunosuppressive therapy [10]. Although there is evidence of adverse events such as organ involvements of CMV diseases and cessation of immunosuppression as a result of CMV reactivation [11], there is a lack of experience and recommendation on antiviral prophylaxis for CMV reactivation in glomerular diseases. The purpose of this study was to identify the frequency of infectious complications in primary glomerulonephritis and clarify their burden to the healthcare managements along with the risk factors contributing to infection.

\section{Materials and Methods}

This was a retrospective, single-center study including 242 adult patients with biopsy-proven focal segmental glomerulosclerosis (FSGS), membranous nephropathy, IgA nephropathy, minimal change disease, membranoproliferative glomerulonephritis, and chronic glomerulonephritis diagnosed between January 2009 and June 2019 and followed up for at least 3 months. We evaluated 364 patients with the diagnosis of glomerulonephritis. We excluded 9 patients with the diagnosis of FSGS related to antineutrophil cytoplasmic antibodies and anti-GBM; 15 patients were excluded because of $<3$ months of follow-up time and 98 patients were lost to follow-up. An infectious episode was defined as a clinically confirmed infection requiring antimicrobial treatment. If there was a documented responsible agent, it was denoted. Immunosuppressive treatments were applied according to KDIGO guidelines after 2012 and our center's clinical practice - before [12].

We recorded the demographic and clinical characteristics, treatment modalities, and antimicrobial prophylaxis status of the patients. Infectious event-related data were collected as frequency of infection, infection occurring time after the diagnosis, area of the infection (lungs, genitourinary system, skin and soft tissue, upper respiratory tract, gastrointestinal system, sepsis, joints, and bone), responsible infectious agents (bacteria, virus, or fungus), and rate of infection-related mortality. We retrieved the number and duration of admissions, infection related or otherwise, to the emergency department, intensive care unit, or inpatient units. We recorded the need for renal replacement therapy and the time passed after the diagnosis until the renal replacement therapy. Laboratory results were collected at the time of diagnosis; at 1, 3, 6, and 12 months after the diagnosis; and then every 12 months until the last follow-up. Proteinuria level was graded as $<1,1-3,>3$, and $>10 \mathrm{~g}$. Renal function was denoted with the estimated glomerular filtration rate (eGFR) calculated according to the Chronic Kidney Disease Epidemiology Collaboration (CKD-EPI) formula and creatinine level [13].

\section{Statistical Analysis}

Clinical and laboratory data are expressed as percentages, means $( \pm S D)$, or medians (interquartile range $[\mathrm{IQR}]$ ), as appropriate. Continuous variables in the characteristics of the 2 groups were compared by the $t$ test or Mann-Whitney $U$ test and categorical variables with Pearson's $\chi^{2}$ or Fisher's exact test. Logistic regression analyses were performed to study associations between "immunosuppression/infection" (dependent variable) and predictor variables. Parameters with a $p$ value $<0.2$ in univariate analysis were considered for entry in the multiple logistic regression model. The quality of adjustment of the model was tested with the Hosmer-Lemeshow statistic. Odds ratios are expressed with $95 \%$ confidence intervals (CIs). A threshold value of $p<0.05$ was considered as statistically significant. The calculations were made with IBM SPSS 11.5 (SPSS Inc., Chicago, IL, USA).

\section{Results}

\section{Main Characteristics of the Patients}

We evaluated 242 patients (114 females, 128 males) with a median follow-up of 31 months. The mean age of 
Table 1. Main characteristics of patients at diagnosis
Fig. 1. Immunosuppressive treatments. MMF, mycophenolate mofetil.
Female, $n /$ male, $n$

Age, mean $\pm \mathrm{SD}$, years

Renal pathology, $n, \%$

Membranous nephropathy

FSGS

IgA nephropathy

Minimal change disease

Membranoproliferative glomerulonephritis

Chronic glomerulonephritis

Serum Cr, median (IQR), mg/dL

eGFR, median (IQR), $\mathrm{mL} / \mathrm{min} / 1.73 \mathrm{~m}^{2}$

Proteinuria, median (IQR), mg/day

Proteinurias, \%

$$
\begin{aligned}
& <1 \text { g/day } \\
& 1-3 \text { g/day } \\
& >3 \text { g/day }
\end{aligned}
$$$$
>10 \text { g/day }
$$

Serum albumin, median (IQR), g/dL

Serum IgG, median (IQR) (7.51-15.6 g/L)

Antimicrobial prophylaxis, $n$, \%

Patients with at least one infectious episode, $n, \%$
$114 / 128$

$44.4 \pm 14.3$

$78,32.2$

$68,28.1$

$57,23.6$

$23,9.5$

$6,2.5$

$10,4.1$

$1.08(0.7-1.7)$

$68.6(39.1-105)$

$4,923(2,349-7,317)$

6.2

27.3

55

11.6

$2.95(2.2-3.7)$

$7.96(5-10.7)$

$52,33.8$

$84,34.7$

SD, standard deviation; eGFR, estimated glomerular filtration rate; IQR, interquartile range; FSGS, focal segmental glomerulosclerosis.

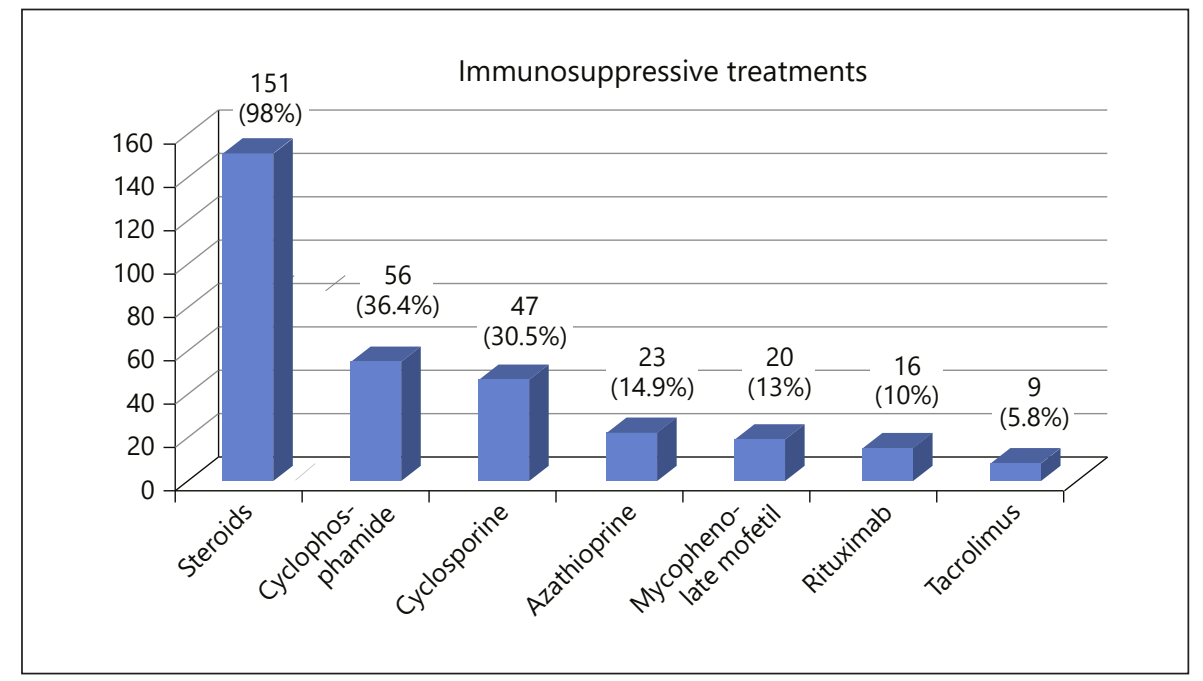

the patients was $44.4 \pm 14.3$ years. The most frequent renal pathology was membranous glomerulonephritis. The median creatinine level was $1.08 \mathrm{mg} / \mathrm{dL}$ (IQR, 0.7-1.7), eGFR level was $68.6 \mathrm{~mL} / \mathrm{min} / 1.73 \mathrm{~m}^{2}$ (IQR, 39.1-105), $55 \%$ of patients had $>3 \mathrm{~g} /$ day proteinuria, and $11.6 \%$ of patients had $>10 \mathrm{~g} /$ day proteinuria at diagnosis. Demographic characteristics at the time of diagnosis and the results are summarized in Table 1.

Of the patients, $154(63.6 \%)$ received immunosuppressive treatment and $88(34.4 \%)$ were followed up un- der conservative treatment. In all, $98 \%$ of those immunosuppressive treatments were corticosteroids, $36.4 \%$ were cyclophosphamide, $13 \%$ were MMF, $14.9 \%$ were azathioprine, $30.5 \%$ were cyclosporine, $5.8 \%$ were tacrolimus, and $10.4 \%$ were rituximab (shown in Fig. 1). Treatments were given alone or in combination. Steroids were the most frequent first-line choice; $63.6 \%$ of patients achieved remission with first-line immunosuppressives; however, 26.4\% needed second-line, 9.1\% needed third-line, $2.1 \%$ needed fourth-line treatment. 
Table 2. Comparison of clinical characteristics of patients with and without immunosuppressive therapy

\begin{tabular}{|c|c|c|c|}
\hline Parameter & $\begin{array}{l}\text { Immunosuppressive } \\
\text { therapy }(+), n=154\end{array}$ & $\begin{array}{l}\text { Immunosuppressive } \\
\text { therapy }(-), n=88\end{array}$ & $p$ value \\
\hline Female/male, $n, \%$ & $74,48.1 / 80,51.9$ & $40,45.5 / 48,54.5$ & 0.789 \\
\hline Age, mean $\pm S D$, years & $44.7 \pm 14.6$ & $44 \pm 13.8$ & 0.720 \\
\hline Follow-up, median (IQR), months & $24(8-49)$ & $21(4-43.75)$ & 0.360 \\
\hline eGFR-0, median (IQR), $\mathrm{mL} / \mathrm{min} / 1.73 \mathrm{~m}^{2}$ & $80.6(46-109)$ & $54.06(25.9-86.5)$ & $<0.0001$ \\
\hline eGFR-end, median (IQR), mL/min/1.73 m² & $85(55-90)$ & $61(20-90)$ & $<0.0001$ \\
\hline Serum albumin-0, median (IQR), g/dL & $2.55(2-3.32)$ & $3.6(2.92-4)$ & $<0.0001$ \\
\hline Proteinuria-0, median (IQR), g/day & $5,494(3,604-5,494)$ & $2,527(1,606-4,298)$ & $<0.0001$ \\
\hline Serum IgG, median (IQR) (7.51-15.6 g/L) & $6.5(4.3-9.2)$ & $9.5(7.75-12)$ & $<0.0001$ \\
\hline Infection $(+), n, \%$ & $64,42.1$ & $20,23.3$ & 0.005 \\
\hline Infection-related hospitalization, $n, \%$ & $40,26.1$ & $11,12.5$ & 0.014 \\
\hline Infection attack, mean $\pm \mathrm{SD} /$ median $(\mathrm{IQR})$ & $0.76 \pm 1.1 / 0(0-5)$ & $0.26 \pm 0.49 / 0(0-1)$ & 0.001 \\
\hline Time interval between the diagnosis and infection, median (IQR), months & $3(1-8)$ & $3.5(1-21)$ & 0.844 \\
\hline Emergency admissions, mean $\pm \mathrm{SD} /$ median $(\min -\max )$ & $0.48 \pm 1.1 / 0(0-10)$ & $0.31 \pm 0.89 / 0(0-5)$ & 0.104 \\
\hline Infection-related emergency admissions, mean $\pm \mathrm{SD} /$ median (min-max) & $0.17 \pm 0.45 / 0(0-3)$ & $0.8 \pm 0.27 / 0(0-1)$ & 0.135 \\
\hline Total hospitalization, mean $\pm \mathrm{SD} /$ median $(\min -\max )$ & $1.83 \pm 1.28 / 1(1-7)$ & $1.40 \pm 1.25 / 1(1-7)$ & 0.02 \\
\hline Noninfectious hospitalization, $n, \%$ & $70,45.5$ & $24,27.3$ & 0.004 \\
\hline Infection-related hospitalization, $n, \%$ & $40,26.1$ & $11,12.5$ & 0.014 \\
\hline Infection-related hospitalization, mean $\pm \mathrm{SD} /$ median $(\min -\max )$ & $0.33 \pm 0.61 / 0(0-3)$ & $0.13 \pm 0.37 / 0(0-2)$ & 0.011 \\
\hline Infection-related hospitalization days, mean $\pm \mathrm{SD} /$ median $(\min -\max )$ & $5.5 \pm 14.61 / 0(0-128)$ & $2.06 \pm 7.68 / 0(0-47)$ & 0.011 \\
\hline Intensive care admission days, mean $\pm \mathrm{SD} /$ median (min-max) & $1.03 \pm 9.1 / 0(0-110)$ & $0.07 \pm 0.74 / 0(0-7)$ & 0.33 \\
\hline Infection-related ICU admission, $n, \%$ & $8,5.2$ & $1,1.1$ & 0.161 \\
\hline Infection-related mortality rate, $n, \%$ & $6,3.9$ & $2,2.3$ & 0.714 \\
\hline $\mathrm{RRT}, n, \%$ & $9,5.8$ & $24,27.3$ & $<0.0001$ \\
\hline Time interval between diagnosis and RRT, median (IQR), months & $7.5(1-33)$ & $3(1-23)$ & 0.867 \\
\hline
\end{tabular}

SD, standard deviation; eGFR, estimated glomerular filtration rate; IQR, interquartile range; ICU, intensive care unit; RRT, renal replacement therapy.

Only 1 patient received fifth-line treatment according to KDIGO guidelines.

Antimicrobial prophylaxis was given to $33.8 \%$ of the patients. Prophylactic drugs were given alone or in combination, and they were as follows: trimethoprim-sulfamethoxazole (TMP-SMX) $(n=42)$, fluconazole $(n=29)$, izoniazid $(n=4)$, acyclovir $(n=4)$, entecavir $(n=2)$, tenofovir $(n=2)$, and lamivudine $(n=2)$.

\section{Comparison of Clinical Characteristics of Patients with and without Immunosuppressive Therapy}

Characteristics of the patients with and without immunosuppressive therapy are shown in Table 2 . Total infectious complications were compared based on whether or not an infection occurred, and were found to be higher in the immunosuppressive group than in the conservative group ( 42.1 vs. $23.3 \%, p=0.005$ ). Percentages of whether or not an infection-related hospitalization happened were also higher (26.1 vs. $12.5 \%, p=0.01)$.
The rate of emergency admissions was not different between the 2 groups. However, total and noninfectious hospitalization rate, number of hospitalizations due to infection, and duration of infection-related hospitalization were higher in the immunosuppressive group than in the conservative group (Table 2).

Although infection-related ICU admissions and mortality were higher in the immunosuppressive group than in the conservative group $(8,5.2 \%$ vs. $1,1.1 \%, p=0.161$; $6,3.9 \%$ vs. $2,2.3 \%, p=0.714$, respectively) because of the small patient number, they did not reach the significant level. Fatal infections were pneumonia and septic shock.

In total, 29 patients became dialysis dependent and 4 patients received kidney transplantation. In the patients treated with an immunosuppression protocol, the number of patients who progressed to end-stage kidney disease was lower than the rest ( 5.8 vs. $27.3 \%, p<0.0001$ ). Dialysis initiation time after the diagnosis was not different (Table 2).

The areas most frequently infected was the lungs (15.7\%), genitourinary system (12.8\%), skin/soft tissue
60
Eren Sadioglu et al. 
Table 3. Infectious episode characteristics

\begin{tabular}{|c|c|c|c|}
\hline Parameter & $\begin{array}{l}\text { Immunosuppressive } \\
\text { therapy }(+), n=154\end{array}$ & $\begin{array}{l}\text { Immunosuppressive } \\
\text { therapy }(-), n=88\end{array}$ & Overall \\
\hline \multicolumn{4}{|l|}{ Infected areas, $n, \%$ (all episodes) } \\
\hline Lungs & $33,21.4$ & $5,5.68$ & $38,15.7$ \\
\hline Upper respiratory tract & $9,5.8$ & $1,1.1$ & $10,4.1$ \\
\hline Gastrointestinal system & $4,2.5$ & $1,1.1$ & 5,2 \\
\hline Genitourinary system & $23,14.9$ & 8,9 & $31,12.8$ \\
\hline Skin/soft tissue & $9,5.8$ & $3,1.2$ & $12,4.9$ \\
\hline Joint and bone & 0 & $1,0.4$ & $1,0.4$ \\
\hline \multicolumn{4}{|l|}{ Infection } \\
\hline Sepsis & $3,1.9$ & 0 & $3,1.23$ \\
\hline Viremia & $9,1.29$ & 0 & $9,3.71$ \\
\hline \multicolumn{4}{|l|}{ Infected areas, $n, \%$ (first episode) } \\
\hline Lungs & $27,42.2$ & 6,30 & $33,13.6$ \\
\hline Upper respiratory tract & $5,7.8$ & 1,5 & $6,2.47$ \\
\hline Gastrointestinal system & $1,1.6$ & 1,5 & $2,0.8$ \\
\hline Genitourinary system & $17,26.6$ & 8,40 & $25,10.3$ \\
\hline Skin/soft tissue & $7,10.9$ & 3,15 & $10,4.13$ \\
\hline Joint and bone & 0 & 1,5 & $1,0.4$ \\
\hline \multicolumn{4}{|l|}{ Infection } \\
\hline Sepsis & $2,3.1$ & 0 & $2,0.82$ \\
\hline Viremia & $5,7.8$ & 0 & 5,2 \\
\hline \multicolumn{4}{|l|}{ Infectious agent, $n, \%$ (all episodes) } \\
\hline Bacterial & $56,36.3$ & $18,20.4$ & $74,30.5$ \\
\hline Viral & 17,11 & $2,2.2$ & $19,7.8$ \\
\hline Fungal & $2,1.29$ & 0 & $2,0.8$ \\
\hline \multicolumn{4}{|l|}{ Infectious agent, $n, \%$ (first episode) } \\
\hline Bacterial & $51,79.7$ & $17,89.5$ & 68,28 \\
\hline Viral & $12,18.8$ & $2,10.5$ & $14,5.7$ \\
\hline Fungal & $1,1.6$ & 0 & $1,0.4$ \\
\hline CMV infection/reactivation, $n, \%$ & $23,14.9$ & 0 & \\
\hline CMV DNA checked, $n, \%$ & - & - & 63,41 \\
\hline CMV-related hospitalization, $n, \%$ & $8,5.1$ & 0 & \\
\hline
\end{tabular}

CMV, cytomegalovirus.

(5\%), and upper respiratory tract (4.1\%). Thinking it is the most related, we compared the first infectious event after the diagnosis, and there was no difference between the 2 groups regarding the infection area or infectious agent (Table 3).

Bacterial infections were the most common in both groups; while $14.9 \%$ of patients receiving immunosuppressive therapy had CMV replication and/or infection $(n=23)$, there was no CMV replication in the conservative group. CMV DNA was checked for only 63 of the patients in the immunosuppressive group (40.9\%). Eight of the patients (34.7\%) who had CMV reactivation needed hospital admission for antiviral treatment.

Three patients experienced zona zoster, and 1 patient was diagnosed with tuberculous lymphadenitis. There were 3 cases of pulmonary Pneumocystis jirovecii and 1 case of invasive aspergillosis. Six patients received hepatitis $\mathrm{B}$ prophylaxis, and no hepatitis reactivation occurred.

\section{Comparisons of Patients in the Immunosuppressive Group}

We also compared characteristics of the patients regarding infection in the immunosuppressive group ( $\mathrm{Ta}$ ble 4). On the whole, 118 infectious episodes were noted in 64 patients, with an infection rate of 0.20 per patientyear. The median time interval between the diagnosis and first infection was 3 months (IQR 1-11). Age and initial proteinuria were higher, and albumin level at diagnosis was lower in the patients who had at least one infectious 
Table 4. Comparisons of patients in the immunosuppressive group regarding infections

\begin{tabular}{|c|c|c|c|c|}
\hline Parameter & $\begin{array}{l}\text { Infection (+), } \\
n=64\end{array}$ & $\begin{array}{l}\text { Infection (-), } \\
n=90\end{array}$ & $\begin{array}{l}\text { Rate of } \\
\text { infection }\end{array}$ & $p$ value \\
\hline Age, mean $\pm S D$, years & $47.7 \pm 13.9$ & $42.3 \pm 14.6$ & - & 0.022 \\
\hline Female/male, $n, \%$ & $37,56.3 \% / 27,43.8 \%$ & $37,42 \% / 53,58 \%$ & - & 0.059 \\
\hline eGFR-0, median (IQR), $\mathrm{mL} / \mathrm{min} / 1.73 \mathrm{~m}^{2}$ & $80(48-102)$ & $82.1(46.1-121.3)$ & - & 0.345 \\
\hline Proteinuria, median (IQR), g/day & $5,861(4,539-9,437)$ & $5,046(3,113-6,894)$ & - & 0.008 \\
\hline Serum albumin, median (IQR), g/dL & $2.2(1.7-3)$ & $2.75(2.2-3.5)$ & - & 0.002 \\
\hline Serum IgG, median (IQR) $(7.51-15.6 \mathrm{~g} / \mathrm{L})$ & $6.2(3.6-8.7)$ & $7(4.8-10.4)$ & - & 0.087 \\
\hline Cyclophosphamide, $n, \%$ & 32,50 & $24,27.3$ & $57 \%(32 / 56)$ & 0.006 \\
\hline MMF, $n, \%$ & $11,17.2$ & $9,10.2$ & $55 \%(11 / 20)$ & 0.232 \\
\hline Azathioprine, $n, \%$ & $10,15.6$ & $13,14.8$ & $43 \%(10 / 23)$ & 1 \\
\hline Cyclosporine, $n, \%$ & $25,30.9$ & 22,25 & $53 \%(25 / 47)$ & 0.76 \\
\hline Tacrolimus, $n, \%$ & $5,7.8$ & $4,4.5$ & $55 \%(5 / 9)$ & 0.494 \\
\hline Rituximab, $n, \%$ & $5,7.8$ & $11,12.5$ & $31 \%(5 / 16)$ & 0.429 \\
\hline Prophylactic drugs, $n, \%$ & $24,37.5$ & $28,31.8$ & - & 0.492 \\
\hline
\end{tabular}

SD, standard deviation; eGFR, estimated glomerular filtration rate; IQR, interquartile range; MMF, mycophenolate mofetil.

Table 5. Multivariate analysis results for the risk factors for infectious complications

\begin{tabular}{|c|c|c|c|c|}
\hline \multirow[b]{2}{*}{ Parameter } & \multicolumn{2}{|c|}{ Univariate } & \multicolumn{2}{|c|}{ Multivariate } \\
\hline & $p$ value & odds ratio $(95 \% \mathrm{CI})$ & $p$ value & odds ratio $(95 \% \mathrm{CI})$ \\
\hline Age $>50$ years & 0.006 & $2.139(1.242-3.683)$ & 0.03 & $2.195(1.05-4.58)$ \\
\hline Gender (reference: male) & 0.182 & $1.438(0.844-2.451)$ & ns & \\
\hline Serum albumin $<2.5, \mathrm{~g} / \mathrm{dL}$ & $<0.0001$ & $3.054(1.756-5.321)$ & 0.02 & $2.289(1.09-4.77)$ \\
\hline Serum IgG level, g/L & 0.065 & $0.934(0.870-1.004)$ & ns & \\
\hline \multicolumn{5}{|l|}{ Proteinuria, } \\
\hline <1 g/day (reference) & 0.047 & - & ns & \\
\hline $1-3 \mathrm{~g} /$ day & 0.706 & $1.306(0.327-5.219)$ & & \\
\hline$>3$ g/day & 0.162 & $2.550(0.686-9.479)$ & & \\
\hline$>10 \mathrm{~g} /$ day & 0.064 & $4.0(0.923-17.329)$ & & \\
\hline Cyclophosphamide & 0.004 & $2.708(1.375-5.334)$ & 0.02 & $2.430(1.13-5.19)$ \\
\hline Cyclosporine & 0.060 & $1.952(0.974-3.915)$ & 0.03 & $2.301(1.05-5.03)$ \\
\hline
\end{tabular}

episode (infection+ group) than the patients without any history of infection (infection- group). Initial eGFR was the same between the groups. The median IgG level at diagnosis tended to be lower in the infection+ group (6.2 vs. $7, p=0.087$ ); however, it was not statistically associated with infectious episodes. In all, 50\% of the patients in the infection+ group had received cyclophosphamide. We checked all the infectious episodes in patients who received an immunosuppressant agent separately, and the rate of infections is presented in Table 4.

Interestingly, 24 of 52 patients who received a prophylactic antimicrobial drug had experienced an infection.
All these patients received corticosteroids, 16 had cyclophosphamide, 13 had cyclosporine, 5 had azathioprine, 4 had MMF, 4 had rituximab, and 3 had tacrolimus in various orders and treatment lines.

\section{Risk Factors for Infectious Complications}

To determine the independent risk factors for infectious episodes, we conducted logistic regression analysis. Gender (female), age, serum IgG, serum albumin, cyclophosphamide, and cyclosporine were considered as risk factors for the reason that their $p$ values were $<0.20$ in the univariate analysis. Multivariate regression analyses re- 
vealed that age $>50$ years, serum albumin $<2.5 \mathrm{~g} / \mathrm{dL}$ at diagnosis, cyclophosphamide, and cyclosporine were independently associated with experiencing at least one infectious episode (Table 5).

\section{Discussion/Conclusion}

This study revealed that almost half of the patients who received immunosuppressive therapy experienced at least one infectious episode, and infections were much more frequent than in the patients who have been followed up under conservative treatment. Infection-related mortality and hospitalizations including ICU and emergency department were also significantly higher with immunosuppressive treatments. The risk of infection independently increased with age, hypoalbuminemia, and cyclophosphamide and cyclosporine treatments.

In McQuarrie et al.'s [14] study, there were infectious episodes in $18 \%$ of the patients who had been treated with alkylating agents, while there were none in patients treated with cyclosporine. Rauen et al. [5] and Lv et al. [15] reported similarly high rates of severe infections among the immunosuppressive group ( 8.1 vs. 9.8\%), including 1 and 2 deaths, respectively, in their studies on patients with IgA nephropathy. Duncan et al. [16] presented their experiences with 6 patients who were treated with tacrolimus monotherapy for FSGS. There was only one urinary tract infection not requiring hospitalization [16]. Because all of these studies were investigating a particular diagnosis and/or specific agents, comparing our data with them was challenging.

In Trivin et al.'s [7] comprehensive study on 98 patients who received rituximab, the infection rate was 21.6 per 100 patient-year (25.5\%). They included several diagnoses requiring rituximab, such as cryoglobulinemia-associated nephropathy, MGN, SLE, and AAV. They found a higher incidence of infections than other studies [17, 18], and they argued that it was related to underlying nephritis, concomitant diseases (diabetes), medications (azathioprine), and renal insufficiency (eGFR $<45 \mathrm{~mL}$ / $\min / 1.73 \mathrm{~m}^{2}$ ). However, they did not have a control group to compare the results with.

In their unpublished study, Glenn et al. [19] found an infection rate of 0.08 per person-year among 1,965 patients with primary glomerulonephritis, and they also discussed hospitalizations and emergency department visits (10\%) due to infection. In all, 9\% of infections required ICU admission. They found age, black race, and comorbidites to be risk factors for infection in their recent un- published study as well [20]. Still, they did not analyze the outcome regarding immunosuppressive treatment.

On the whole, in our study, $34.7 \%$ of infectious events were recorded, and $42.1 \%$ of the patients who had been treated with an immunosuppressive dealed with infectious complications. We found an infection rate of 0.20 in the immunosuppressive group; $26.1 \%$ of the infectious episodes ended with admission to hospital and 5.2\% of infections required ICU admission. Due to the heterogeneity of diagnosis and treatments and possible geographical differences regarding infectious agents, it is hard to compare the rates of infection with other studies.

In most clinical trials regarding primary glomerulonephritis, serious infectious events are reported, instead of every infectious episode. On the other hand, in some SLE trials that report any infection, there were even higher rates of infections [4]. One possible explanation for the higher incidence of infectious complications in our study might be that we recorded all documented infections requiring antimicrobial treatment. However, it is important to know about all possible infectious complications for better patient care and healthcare utilization.

Since 1942, with the usage of antibiotics, death from infection has decreased. However, with more intensive immunosuppressive regimens and different effects of them, in order to decrease the infectious complications, screening for infections and using prophylactic antimicrobials came to the fore. In the latest KDIGO Clinical Practice Guideline on Glomerulonephritis (Public Review Draft) [21], it is recommended that prophylactic TMP-SMX should be administered during periods of high-dose prednisone therapy and advised with rituximab. However, the role of prohpylaxis with TMP-SMX in patients on high-dose corticosteroid therapy without HIV infection remains controversial [22]. In our study, $33.8 \%$ of the patients received it; however, infection rates were not different from those who did not receive it.

We found $14.9 \%$ CMV replication and/or infection in the immunosuppressive group, which is lower than the data regarding CMV reactivation after renal transplantation in the developing part of the world $[23,24]$. However, it is possible that our study underestimated it: CMV DNA was checked in only $41 \%$ of the patients in the immunosuppressive group. Celebi et al. [11] reported CMV DNA positivity with a clinical sign as $19.2 \%$ in their study encompassing all glomerular diseases including SLE and AAV. Across the world, the overall seroprevalence of CMV ranges from 40 to $100 \%$ [25], and seropositivity for CMV was shown to be high (93.6\%) in Turkey [10]. Because of local healthcare policies, it is not possible to give 
prophylactic antiviral treatment for CMV in glomerulonephritis in Turkey. All in all, our study raised an idea that adoption of preemptive strategy might be judicious in CMV replication, especially in high-risk patients with primary glomerulonephritis in countries where CMV seroprevalence is high.

According to the KDIGO practice guideline on glomerulonephritis, patients with glomerulonephritis should receive pneumococcal vaccination as well as the annual influenza vaccination [12]. We could not give a frequency regarding $S$. pneumoniae infections as our data on the documention of responsible agent was not solid for pneumonia. We were not able to find vaccination data, which was a limitation for our study.

Hypogammaglobulinemia has been known to be a risk factor for infections in nephrotic syndrome for a long time. Additionally, there are limited data that show infection risk is reduced by i.v. immunoglobulin (IVIG) administration if serum IgG is less than $6 \mathrm{~g} / \mathrm{L}$ [26]. In our study, even though the serum IgG level was found to be lower in the infection+ group, it was not significant. There were no patients who received i.v. immunoglobulin. Nevertheless, IgG level came up as a candidate risk factor for infection in univariate analysis. It was probable that our study was not expansive enough to show this relation due to the small number of patients.

It has been shown that lupus nephritis is associated with higher healthcare utilization than normal controls. Additionally, SLE patients with renal damage incurred higher direct costs than those without nephritis [27, 28]. However, there is no existing data indicating high cost or high rate of using healthcare regarding infections in glomerulonephritis. In our study, we showed that hospitalizations including emergency department visits and ICU were higher in patients experiencing infectious episodes.

We found that severe hypoalbuminemia at diagnosis was an independent risk factor for infection. It is hard to specify a certain underlying mechanism for this finding. It could be a risk factor by affecting the free fraction of the drug interacting with the drug receptor [29]. With that being said, Minatoguchi et al.'s [30] findings showed that the serum albumin level was a significant risk factor for infection-related in-hospital death among hemodialysis patients.

In glomerulonephritis, immunosuppressive treatment is occasionally used with steroids, and if the disease does not remit, sequential treatments are needed. Comparison of infections is confounded by simultaneous immunosuppressants. Cavallasca et al.'s [31] study in cyclophos- phamide-treated patients, $50 \%$ of whom had glomerulonephritis, showed 15\% infectious episodes. Additionally, they showed that high cumulative glucocorticoid dose was associated with infections [31]. Similarly, Celebi et al. [11] demonstrated cyclophosphamide with corticosteroid treatment as an independent risk factor for CMV disease development in their study. In an old review, they presented that cyclosporine was not associated with infections in the setting of autoimmune disease. Furthermore, in some studies with transplantation patients, infection rate was even lower in patients receiving solely cyclosporine than in patients who received azathioprine, ATG, and/or corticosteroids [32]. In our study, although we were not be able to calculate their cumulative doses, cyclophosphamide and cyclosporine were used together with corticosteroids in all patients. Additionally, cyclosporine was frequently used as a second- or third-line treatment. It is possible that a probable synergistic effect of combination therapies on the immune system and cumulative immunosuppression could be the determinants why we found cyclophosphamide and cyclosporine as risk factors for infection.

Lim et al. [33] described a risk stratification for deciding antiviral prophylaxis for CMV replication in glomerular diseases treated with potent immunosuppressants. Although the study did not have sufficient number of patients, they demonstrated that CMV disease was more frequent in the group that did not receive prophylaxis than in those given antiviral prophylaxis. However, they implicated that adverse events (40\%) related to antiviral drugs were a matter of concern. In the CANVAS trial [34], $38 \mathrm{CMV}$ seropositive AAV patients were enrolled and randomized to 6 months of valaciclovir or no anti-treatment. There was no CMV reactivation in patients receiving valaciclovir, whereas reactivation was detected in $4(21 \%)$ control patients. Valaciclovir was not found to be related to any adverse events in that report. Because there are no certain recommendations for giving antiviral prophylaxis or monitoring CMV PCR levels in glomerulonephritis as in solid organ transplantations, comprehensive studies are needed on this particular subject.

There are several limitations in our study. First, it has a retrospective design and a relatively small sample size. Second, our disease profile was heterogeneous regarding either diagnosis or treatments. Third, we were not able to record the cumulative dose of the treatments and vaccination status of the patients. Additionally, not all of the infectious episodes were concretized by cultures. 
Nonetheless, we included all primary glomerulonephritis patients in our center with sufficient follow-up time to the study; we recorded all infectious episodes with hospitalization rate and duration and investigated risk factors in our study. We think this detailed and comprehensive study might help manage primary glomerulonephritis.

In conclusion, infections after using immunosuppressive agents, especially with cyclophosphamide and/ or cyclosporine, must be considered as a strong reason for poor patient outcome and increased usage of hospital sources. Because of the high seropositivity for CMV in Turkey, it be might a wise approach to use prophylactic antiviral drugs for those patients who were treated with immunosuppressive therapy. Close monitoring of patients with primary glomerulonephritis, especially those treated with immunosuppressive therapy, is important for reducing infection-related morbidity and mortality.

\section{Acknowledgements}

The abstract of this study has been accepted as a poster presentation at the International Society of Nephrology Congress 2020.

\section{Statement of Ethics}

All procedures performed in studies involving human participants were in accordance with the ethical standards of Ankara University School of Medicine Ethics Committee for Clinical Studies at which the studies were conducted (Approval number: I1-65-20) and with the 1964 Helsinki Declaration and its later amendments or comparable ethical standards. Written informed consent was obtained from all the patients at the time of performing a renal biopsy.

\section{Conflict of Interest Statement}

The authors have no conflict of interest to declare.

\section{Funding Sources}

The authors have no funding to declare.

\section{Author Contributions}

All authors were involved in the following: conception or design, or analysis and interpretation of data, or both; drafting the manuscript or revising it; providing intellectual content of critical importance to the work described; and final approval of the version to be published.

\section{References}

1 Feehally J, Floege J, Tonelli M, Johnson RJ. Introduction to glomerular disease. In Comprehensive Clinical Nephrology. Philadelphia: Elsevier Saunders; 2010. p. 184-98.

2 Arneil GC. 164 children with nephrosis. Lancet. 1961;2(7212):1103-10.

3 Wu HM, Tang JL, Cao L, Sha ZH, Li Y. Interventions for preventing infection in nephrotic syndrome. Cochrane Database Syst Rev. 2012;4(4):CD003964.

4 Jefferson JA. Complications of immunosuppression in glomerular disease. Clin J Am Soc Nephrol. 2018;13(8):1264-75.

5 Rauen T, Eitner F, Fitzner C, Floege J. Con: STOP immunosuppression in IgA nephropathy. Nephrol Dial Transplant. 2016;31(11): 1771-4.

6 Howman A, Chapman TL, Langdon MM, Ferguson C, Adu D, Feehally J, et al. Immunosuppression for progressive membranous nephropathy: a UK randomised controlled trial. Lancet. 2013;381(9868):744-51.

7 Trivin C, Tran A, Moulin B, Choukroun G, Gatault P, Courivaud C, et al. Infectious complications of a rituximab-based immunosuppressive regimen in patients with glomerular disease. Clin Kidney J. 2017;10(4): 461-9.
8 Turkish Statistical Institute. The results of address based population registration system. 2019. http: //www.turkstat.gov.tr/HbGetirHTML.do?id=33705.

9 Turkish Statistical Institute. Causes of death statistics, 2018. http://www.turkstat.gov.tr/ PreHaberBultenleri.do?id=30626.

10 Ataman S, Colak D, Günseren F, Senol Y, Colak T, Aktekin MR, et al. [Investigation of cytomegalovirus seroepidemiology in Antalya with a population-based cross-sectional study and review of related data in Turkey]. Mikrobiyol Bul. 2007;41(4):54555.

11 Celebi ZK, Calayoglu R, Yalcı AK, Akturk S, Sengul S, Kutlay S, et al. Cytomegalovirus disease in patients with glomerular diseases treated by immunosuppressive treatment. Int Urol Nephrol. 2014;46(12):2357-60.

12 Radhakrishnan J, Cattran DC. The KDIGO practice guideline on glomerulonephritis: reading between the (guide)lines: application to the individual patient. Kidney Int. 2012; 82(8):840-56.

13 Levey AS, Stevens LA, Schmid CH, Zhang YL, Castro AF 3rd, Feldman HI, et al. A new equation to estimate glomerular filtration rate. Ann Intern Med. 2009;150(9): 604-12.
14 McQuarrie EP, Stirling CM, Geddes CC. Idiopathic membranous nephropathy and nephrotic syndrome: outcome in the era of evidence-based therapy. Nephrol Dial Transplant. 2012;27(1):235-42.

15 Lv J, Zhang H, Wong MG, Jardine MJ, Hladunewich $M$, Jha V, et al. Effect of oral methylprednisolone on clinical outcomes in patients with IgA nephropathy: the TESTING randomized clinical trial. JAMA. 2017;318(5):432-42.

16 Duncan N, Dhaygude A, Owen J, Cairns TD, Griffith M, McLean AG, et al. Treatment of focal and segmental glomerulosclerosis in adults with tacrolimus monotherapy. Nephrol Dial Transplant. 2004;19(12):3062-7.

17 Terrier B, Amoura Z, Ravaud P, Hachulla E, Jouenne R, Combe B, et al. Safety and efficacy of rituximab in systemic lupus erythematosus: results from 136 patients from the French AutoImmunity and Rituximab registry. Arthritis Rheum. 2010;62(8): 2458-66.

18 Rovin BH, Furie R, Latinis K, Looney RJ Fervenza FC, Sanchez-Guerrero J, et al. Efficacy and safety of rituximab in patients with active proliferative lupus nephritis: the lupus nephritis assessment with rituximab study. Arthritis Rheum. 2012;64(4):121526. 
19 Glenn DA, Henderson CD, Hu Y, Zinsser D, O'Shaughnessy MM, Greenbaum LA, et al., editors. Infectious complications in patients with glomerular disease: an analysis of the cure glomerulonephropathy (CureGN) study. San Diego (CA): ASN Kidney Week; 2018.

20 Glenn DA, Henderson $\mathrm{CD}, \mathrm{Hu} \mathrm{Y}$, O'Shaughnessy MM, Greenbaum LA, Zee J, et al., editors. Risk factors for infection in patients with glomerular disease: an analysis of the cure glomerulonephropathy (CureGN) study. Washington: ASN Kidney Week; 2019.

21 Eknoyan G, Lameire N. KDIGO clinical practice guideline on glomerular diseases (public review Draft). 2020.

22 Liebling M, Rubio E, Ie S. Prophylaxis for Pneumocystis jiroveci pneumonia: is it a necessity in pulmonary patients on high-dose, chronic corticosteroid therapy without AIDS? Expert Rev Respir Med. 2015;9(2):171-81.

23 Bhadauria D, Sharma RK, Kaul A, Prasad N, Gupta A, Gupta A, et al. Cytomegalovirus disease in renal transplant recipients: a singlecenter experience. Indian J Microbiol. 2012; 52(3):510-5.
24 Marin LJ, Santos de Carvalho Cardoso E, Bispo Sousa SM, Debortoli de Carvalho L, Marques Filho MF, Raiol MR, et al. Prevalence and clinical aspects of CMV congenital Infection in a low-income population. Virol J. 2016;13:148.

25 Krech U. Complement-fixing antibodies against cytomegalovirus in different parts of the world. Bull World Health Organ. 1973; 49(1):103-6.

26 Ogi M, Yokoyama H, Tomosugi N, Hisada Y, Ohta S, Takaeda M, et al. Risk factors for infection and immunoglobulin replacement therapy in adult nephrotic syndrome. Am J Kidney Dis. 1994;24(3):427-36.

27 Clarke AE, Panopalis P, Petri M, Manzi S, Isenberg DA, Gordon C, et al. SLE patients with renal damage incur higher health care costs. Rheumatology. 2008;47(3):329-33.

28 Furst DE, Clarke A, Fernandes AW, Bancroft T, Gajria K, Greth W, et al. Medical costs and healthcare resource use in patients with lupus nephritis and neuropsychiatric lupus in an insured population. J Med Econ. 2013;16(4): $500-9$.

29 Czock D, Keller F, Rasche FM, Häussler U. Pharmacokinetics and pharmacodynamics of systemically administered glucocorticoids. Clin Pharmacokinet. 2005;44(1):61-98.
30 Minatoguchi S, Nomura A, Imaizumi T, Sasaki S, Ozeki T, Uchida D, et al. Low serum albumin as a risk factor for infection-related in-hospital death among hemodialysis patients hospitalized on suspicion of infectious disease: a Japanese multicenter retrospective cohort study. Ren Replace Ther. 2018;4(1):30.

31 Cavallasca JA, Costa CA, Maliandi MR, Contini LE, Fernandez de Carrera E, Musuruana JL. Severe infections in patients with autoimmune diseases treated with cyclophosphamide. Reumatol Clin. 2015;11(4):221-3.

$32 \mathrm{Kim}$ JH, Perfect JR. Infection and cyclosporine. Rev Infect Dis. 1989;11(5):677-90.

33 Lim CC, Tan BH, Tung YT, Huang H, Hao Y, Mok IYJ, et al. Risk-stratified approach to anti-viral prophylaxis against cytomegalovirus disease in glomerulonephritis and renal vasculitis treated with potent immunosuppressants. Infect Dis. 2019;51(10):745-52.

34 Chanouzas D, Sagmeister M, Dyall L, Ferro C Moss P, Morgan MD, et al. Valaciclovir to prevent cytomegalovirus mediated adverse modulation of the immune system in ANca Associated VASculitis (CANVAS): results of a randomised controlled clinical trial $[\mathrm{Ab}-$ stract no: th-PO816]. J Am Soc Nephrol. 2016;27(Abstract Edition):282A. 